\title{
Mediação: perspectivas conceituais em Educação e Ciência da Informação
}

Rovilson José da Silva

Professor Adjunto do Departamento de Educação (UEL)

Oswaldo Francisco de Almeida Júnior

Professor Associado da UEL e Professor permanente do Programa de Pós-graduação em Ciência da Informação da UNESP- Marília (SP)

http://dx.doi.org/10.1590/1981-5344/2772

O texto aborda o conceito de mediação, utilizado tanto na área de Educação quanto na Ciência da Informação, numa trajetória que transita do aspecto epistemológico do vocábulo até aproximá-lo à perspectiva do materialismo histórico, dialético, marxiano que influencia a obra de Vygotsky (1995) e Bakhtin (1997); também dialoga com Freire (2003) e Almeida Júnior (2015), autores que têm sido utilizados nas áreas em destaque. Nesse âmbito, usa-se o método bibliográfico para discutir perspectivas do conceito de mediar defendido pela Educação e pela Ciência da Informação, tendo como suporte aspectos da teoria vigotskiana. Conclui que ambas as áreas possuem convergências e divergências que podem ser equalizadas para um melhor aproveitamento da mediação em prol da leitura, da formação do leitor em ambas as áreas.

Palavras-chave: Mediação. Educação. Ciência da Informação.

\section{Mediation: conceptual perspectives in Education and Information Science}

The text approaches the mediation concept, used in the area of Education as in Information Science, in a path that goes from the epistemological aspect of the word to 
approximate it to the perspective of the historical materialism, dialectic, marxian that influences the work of Vygotsky (1995) and Bakhtin (1997); it also dialogues with Freire (2003) and Almeida Júnior (2015), authors that have been used in the highlighted areas. In that context, the bibliographical method is used to discuss perspectives on the concept of mediating protected for the Education and for the Science of the Information, tends as support aspects of the Vygotskian theory. It is concluded that both areas have convergences and divergences that can be equalized for a better use of the mediation on behalf of reading and reader's formation in both areas.

Keywords: Mediation. Education. Information Science.

Recebido em 23.04.2016 Aceito em 28.06.2018

\section{Introdução}

O termo mediar tem sido utilizado largamente por inúmeras áreas do conhecimento e com distintas concepções. Nesse texto apresentaremos, em especial, os conceitos que vêm sendo utilizados na Educação e na Ciência da Informação (CI), aventando a possibilidade de convergências conceituais entre elas.

Em busca do conceito disseminado em ambas as áreas, o texto pautar-se-á pela aproximação com o materialismo histórico advindo de Marx e Engels e com autores que, direta ou indiretamente, se coadunam à perspectiva marxiana para sua obra, o como é o caso de Vigotski (1995) ${ }^{1}$, Bakhtin (1997), Freire (2003) e Almeida Júnior (2015), entre outros autores que embasam esta discussão/análise.

A preocupação com a formação de leitores é desafio constante nas áreas anteriormente mencionadas, pois a leitura é um dos mais complexos e completos recursos sócio-históricos para a formação do indivíduo tanto intelectual quanto social; de modo que ele se aproprie do conhecimento e, ao mesmo tempo, torne-se produtor de conhecimento.

Contribuir à efetivação de leitores na escola, por meio da biblioteca, trata-se do desafio para se encontrar qual seria a estratégia adequada que favoreça a interação entre o aluno e a leitura, entre a leitura e a informação; qual seria o papel do professor e do bibliotecário nesse processo como mediadores, enfim, como realizar a mediação adequada em prol da formação de leitores.

Assim, há questões preliminares que discutiremos acerca do que tem sido veiculado em mediação nas áreas de Educação e CI, ou seja: Como conceber a mediação no âmbito dessas áreas? Há convergências?

${ }^{1}$ Embora existam grafias distintas para o nome do autor, nesse estudo utilizaremos esta grafia, conforme Duarte (2011). 
Como mediar a leitura? A informação? $O$ que dizem os especialistas/teóricos de cada área a esse respeito?

Com isso, analisaremos esses e outros aspectos no âmbito da mediação com o intuito de evidenciar o que tem sido produzido a esse respeito, sem, entretanto, dogmatizar ou absolutizar o que se investigou, mas utilizá-lo como parâmetro à reflexão e ampliação, se for necessário.

\section{Mediação: da etimologia linguística ao conceito marxiano}

Nas raízes etimológicas da palavra mediar há transformações registradas do século XIV até 0 século XIX: do latim medius correspondente em português ao adjetivo meio, ou "que está no meio ou entre dois pontos", também se transforma em outros vocábulos, tais como entremeio (séc. XVII) advindo de ontremeyo (séc. XIV), por exemplo. Nesse percurso de transformação lexical desde o latim mear (séc. XIV) para medear (séc. XV), mediare e, posteriormente, para mediar, como é empregado atualmente (CUNHA, 1992, p. 509), muito se deu tanto em relação ao aspecto linguístico quanto ao histórico.

Reconstruir a evolução histórico-linguística de um vocábulo nem sempre oferece precisão do percurso desde as origens aos dias atuais, pois se trabalha com o que existe registrado e não se consegue precisar se houve transformações intermediárias na transposição do verbo mediar para o substantivo mediação. Assim, conforme Cunha (1992, p. 509), o vocábulo latino mediatio-onis/mediador era utilizado no século XVII e, posteriormente no século XIX, foi constatado na língua francesa o termo médiation e, finalmente, a palavra mediação, em português. Embora seja possível resgatar parte do percurso lexical da palavra mediação, entretanto, não há condições de retomá-la com o sentido histórico, social que foi usada em cada época, pois o conceito está ampliado, ressignificado em nosso tempo.

Da etimologia da palavra mediação ao conceito que esse vocábulo adquiriu a partir do materialismo histórico marxiano, no século XIX, o que se evidenciou foi a valorização gradual dessa categoria para a constituição do sujeito, conforme apontam Zuin e Reyes (2010, p. 38):

[...] a categoria de Mediação é essencial para a formação do sujeito, de sua consciência, de sua individualidade. Nas teorias em questão, a linguagem destaca-se como principal mediadora e constituidora dos indivíduos. A categoria de mediação é de fundamental relevância para o materialismo-histórico, pois é nas relações sociais que se constitui o sujeito.

O homem se constitui por sua inter-relação com o mundo, por meio de seu trabalho, das forças produtivas, pois as condições econômicas que o impelem, confrontam-no com as divisões sociais, com a falta de opções e, ao mesmo tempo, as mediações sociais dialeticamente são combustíveis para a libertação do cerceamento coletivo e individual, conforme Konder pondera (1985, p. 68-69): 
O materialismo histórico de Marx e Engels é constatativo e não normativo: ele reconhece que, nas condições de insuficiente desenvolvimento das forças produtivas humanas e de divisão da sociedade em classe, a economia tem imposto, em última análise, opções estreitas aos homens que fazem a história. Isso não significa que a economia vai dominar eternamente os movimentos do sujeito humano. Ao contrário: a dialética aponta na direção de uma libertação mais efetiva do ser humano em relação ao cerceamento de condições econômicas ainda desumanas.

Assim, "[...] as circunstâncias fazem os homens, assim como os homens fazem as circunstâncias" (MARX; ENGELS, 1999, p. 54), também na mediação social o sujeito pode se sentir oprimido pelo meio, aparentemente sem perspectiva, entretanto, será ali na sua própria realidade que encontrará combustível para a reelaboração crítica da realidade, para direcionar o seu olhar sob o que oprime e, assim, compreender que se o indivíduo recebe influência do mundo, também poderá influenciá-lo para a mudança, poderá recriar, reinterpretar a realidade social e atuar sobre ela, conforme Konder (1985, p. 81)

Uma das características essenciais da dialética é o espírito crítico e autocrítico. Assim como examinam constantemente o mundo em que atuam, os dialéticos devem estar sempre dispostos a rever as interpretações em que se baseiam para atuar.

Nesse contexto, a linguagem é um dos recursos primordiais do sujeito para sua inserção e compreensão do mundo, para compreender a si próprio, pois para Bakhtin (1997, p. 37) a palavra é um signo que pode preencher qualquer espécie de função ideológica, como é o caso dos vocábulos mediar e mediação que receberam transformação não apenas em sua escrita, na parte física da palavra, bem como em seu conceito ao longo das condições históricas e sociais de cada época. A palavra compõe o léxico de uma língua e, portanto, está em constante mudança:

A palavra constitui um meio no qual se produzem lentas acumulações quantitativas de mudanças que ainda não tiveram tempo de adquirir uma nova qualidade ideológica, que ainda não tiveram tempo de engendrar uma forma ideológica, nova e acabada. A palavra é capaz de registrar as fases transitórias mais íntimas, mais efêmeras das mudanças sociais (BAKHTIN, 1997, p. 41).

As palavras, para além de seu percurso etimológico, "[...] são tecidas a partir de uma multidão de fios ideológicos e servem de trama a todas as relações sociais em todos os domínios [...]" (BAKHTIN,1997, p. 41). Portanto, mediação tornou-se um conceito contemporâneo nas áreas no âmbito da formação de leitores e de disseminação da informação e áreas afins, mas o emprego desse conceito pode receber contornos diferentes em cada uma delas, como é o caso da Educação e da Ciência da Informação.

\subsection{Mediar em Ciência Da Informação}


Anterior ao conceito de mediação em CI houve, e há, discussões acerca de qual seria o seu objeto: para alguns seria a informação, para outros, a mediação da informação. Para Carvalho e Mattos (2008, p. 139):

[...] é necessário reconhecer, ao menos, dois pontos de extrema relevância para que se dê andamento ao debate sem "ufanismos" e devaneios:

10) a hegemonia do pensamento atual na área da Ciência da Informação entende a Informação como objeto de estudo, e, remar contra a corrente não é nada fácil;

$2^{\circ}$ ) somente a alteração e o reconhecimento teórico do novo objeto de estudo (mediação da informação) não mudará a realidade imediatamente.

À parte dessa discussão, respeitando os estudos e conceitos de cada vertente, este trabalho se voltará à segunda perspectiva, ou seja, à mediação da informação, conforme Arantes (2014, p. 19)

Aparentemente, as ações e as devidas fundamentações da CI buscam o que se poderia chamar de a "satisfação do leitor". Sem o leitor, para que estudar, tratar, organizar, disseminar etc. a informação? O sujeito é a razão de ser dos sistemas informacionais. Ou não? Os sistemas de informação são um meio para atingir um fim: o leitor.

Se o leitor é a finalidade para a qual existem os sistemas de informação, então cabe ao profissional da informação e ao bibliotecário ter a mediação como perspectiva nesse processo. Adiante, com base em Almeida Júnior (2009), a autora reafirma a mediação como o foco no processo de apropriação da informação pelo usuário, uma vez que ele é o sujeito daquele processo.

Com a finalidade de compreender como a CI se relaciona com o conceito mediação em seu âmbito, recorremos inicialmente a Almeida Júnior e Bortolin (2008, p. 67-85) que discutem embrionariamente aspectos que constituirão o conceito, o percurso que a CI tem feito desde a compreensão de disseminação até chegar à mediação da informação e defendem a substituição do termo disseminação largamente empregado na área pelo conceito de mediação, assim os autores propõem:

Acreditamos na mediação como uma ação que deve ser realizada no sentido de somar e não de enfraquecer, pois ser dependente é ser subordinado e o processo de mediar não é isso, pelo contrário a proposta vai no sentido oposto, que ocorra uma troca, uma ampliação na forma de ver/ler o mundo.

A proposição dos autores não ignora o usuário, valoriza sua participação como sujeito que recebe a informação e, concomitantemente, dialoga com ela por meio da mediação, apresentando contraponto à passividade conceitual que o termo disseminação carrega em si, de um fazer menos complexo, apenas aliado à "[...] mera oferta de materiais, a entrega de suportes que possam atender a uma determinada demanda informacional [...]" (ALMEIDA JÚNIOR; BORTOLIN, 2008, p. 71). 
Nessa perspectiva, a mediação da informação, de acordo com Gomes (2014, p.52) possui

[...] o sentido de compartilhamento, de cooperação, de abertura ao diálogo e ao movimento que desestabiliza e estabiliza conhecimentos, de abertura à crítica e à criatividade, de abertura também às intersecções entre o "velho" e o "novo", o que confere a ação mediadora certa característica de substrato ao autoconhecimento e ao entrelaçamento da humildade e da autoestima dos interlocutores dessa ação.

O sentido que a mediação alcança é mais amplo que o da disseminação, pois o profissional da informação, antes mesmo do atendimento direto ao leitor já a iniciou, de forma implícita, desde a seleção de materiais até no "serviço de referência e informação", assim, as diversas ações realizadas nesse percurso já estão no âmbito da mediação da informação (ALMEIDA JÚNIOR; BORTOLIN, 2008, p. 74).

Gomes (2014, p. 5) corrobora as ideias anteriores, posto que a mediação da informação está centrada na relação dialógica e que, portanto, cabe ao profissional da área o trabalho compartilhado e colaborativo de modo a assumir seu protagonismo social, pois ele "age, constrói e interfere no meio" e, assim, constitui-se sujeito que se humaniza e que, ao mesmo tempo, pode ser agente humanizador no meio.

Se a relação do profissional é dialógica, ou seja, há troca entre quem medeia e quem é mediado, pressupõe-se que haverá sempre um pouco de cada pessoa nesse processo, eliminando a possibilidade de neutralidade na mediação da informação, como ainda sustentam algumas perspectivas no âmbito da CI, uma vez que "as ações do profissional da informação não são neutras, não são imparciais e resultam sempre em uma interferência. Esta se contrapõe à ideia de isolamento, passividade" (ALMEIDA JÚNIOR; BORTOLIN, 2008, p. 73).

Posteriormente, na construção do conceito mediação da informação, Almeida Júnior (2009, p. 92) estabeleceu:

[...] toda ação de interferência - realizada pelo profissional da informação -, direta ou indireta; consciente ou inconsciente; singular ou plural; individual ou coletiva; que propicia a apropriação de informação que satisfaça, plena ou parcialmente, uma necessidade informacional.

Os conceitos são dinâmicos, em especial na Ciência da Informação, pois assim como uma pedra bruta necessita ser lapidada para que seu brilho emerja, será preciso burilar arduamente cada aspecto, cada ângulo para que se chegue ao melhor conceito, como Almeida Júnior (2015, p. 20-25) faz ao revisitar seu próprio trabalho anos mais tarde e, para isso, passa a analisar aspectos que levarão à atualização do conceito. Para isso, aponta perspectivas que são necessárias para se revisar o conceito anterior, dentre elas, consideramos: o princípio do inacabamento do ser humano, que conforme Freire (2003, p. 50), "o inacabamento do ser ou 
sua inconclusão é próprio da experiência vital. Onde há vida, há inacabamento".

Para Almeida Júnior (2015) se o humano é um ser inacabado, o mesmo acontece com o conhecimento e com a informação, pois têm sua construção pelo próprio sujeito no processo de mediação. Dessa forma, o vocábulo processo ganha relevância ao se referir à mediação da informação, pois não é um momento estanque, específico dentro da área, mas sim acontece em vários momentos, é dinâmico.

Outro aspecto destacado pelo autor trata-se do contexto da produção da informação até sua mediação, pois cada informação está inserida num contexto histórico social, ideológico, bem como o espaço e os mediadores ali inseridos são elementos que compõem a complexidade da mediação em ambiente informacional.

Em relação à necessidade informacional, Almeida Júnior, argumenta que essa necessidade será sempre mediada, embora nunca seja satisfeita integralmente e nem quem medeia consegue ter exatidão de que ela foi parcial ou totalmente satisfeita.

Para o autor não se concebe informação desvinculada do meio social, histórico ao qual se passa, ou do inacabamento do ser humano e, por extensão, do próprio inacabamento da informação e, portanto, da necessidade da mediação da informação, que é o núcleo epistemológico da área da CI (ALMEIDA JÚNIOR, 2015). Assim, o autor apresenta a reformulação do conceito de mediação da informação:

Toda ação de interferência - realizada em um processo, por um profissional da informação e na ambiência de equipamentos informacionais -, direta ou indireta; consciente ou inconsciente; singular ou plural; individual ou coletiva; visando a apropriação de informação que satisfaça, parcialmente e de maneira momentânea, uma necessidade informacional, gerando conflitos e novas necessidades informacionais.

Ao reformular, o autor ressignifica o papel da ambiência de equipamentos no processo da mediação da informação, pois o entorno da informação a qual se dará a mediação possui um aspecto amplo, complexo e que não se limita a um espaço físico especificamente, ou simplesmente a uma área apenas, mas deve buscar diálogo com áreas afins, entre outros aspectos. Importa destacar, ainda, a preocupação do autor em que se confunda a ação de interferência para apropriação da informação com a manipulação da mesma, ou do leitor.

Embora ainda não seja hegemônica na área de CI a mudança de conceito do objeto da área, é possível constatar que as pesquisas estão em andamento para reflexão, análise e proposição de outra perspectiva para uma área tão nova, mas que se torna cada dia imprescindível para a vida social.

\subsection{Mediação em Educação: perspectiva vigotskiana}


A educação parece universal, quase ubíqua, pois se relaciona com quase todas as áreas, direta ou indiretamente. Há estudos e teóricos que discutem e analisam os fenômenos socioeducacionais, bem como as ações pedagógicas contidas em distintas teorias e maneiras de se interpretar o processo educativo. A cada período da trajetória histórica, a educação também refletiu parte do que a sociedade imaginou ou esperava da instituição escolar.

Há estudiosos, do Brasil e do exterior, que embasam práticas escolares na educação do país e uma das características da Educação é estar aberta a discutir novos conceitos e, muitas vezes, colocá-los em ação pedagógica: há postulados que empreendem desde Piaget, Freire, Montessori, Vigotski entre tantos outros.

Nessa vasta área, a palavra mediação ora é empregada no senso comum, ou seja, não está diretamente relacionada a nenhuma teoria, apenas tornou-se uma repetição cotidiana da fala que denota uma "[...] prática docente espontânea ou quase espontânea, desarmada [...] produz um saber ingênuo, um saber de experiência feito (FREIRE, 2003, p. 38)." Esse emprego não se pauta pelo rigor epistemológico que leva ao processo dialético de reflexão crítica acerca da práxis, do emprego termo e, inclusive, pode levar a interpretações que distorcem o conceito de mediação.

Para além das dissonâncias conceituais, este trabalho aproxima-se da perspectiva Vigotskiana (VIGOTSKI, 1995), além de estabelecer relação com ideias de Bakhtin (1997), uma vez que ambos os autores têm suas teorias, respectivamente psicologia e teoria da linguagem, orientadas pelos pressupostos filosóficos marxianos do materialismo-histórico, que têm a mediação como uma de suas principais categorias.

A concepção pedagógica sócio-histórica de Vigotski vicejou no solo fértil da educação brasileira que a recebeu de "braços abertos", conforme Zanolla (2012, p. 6):

[...] dadas as influências da psicologia sócio-histórica de Vigotski, é possível dizer que a educação recebeu de braços abertos as contribuições da psicologia social e, fundamentalmente, se direcionou no sentido de privilegiar o conceito de representação social na mediação interativa entre sujeito e objeto.

Entretanto, de acordo com Duarte é preciso ponderar a respeito das interpretações que se fizeram e que se fazem a respeito do pensamento de Vigotski no Brasil, muitas vezes, desvinculando-o da perspectiva marxiana e aproximando-o de concepções neoliberais:

[...] estamos questionando a possibilidade de utilização da psicologia vigotskiana para legitimação de concepções ideologicamente articuladas à sociedade capitalista contemporânea, não importa se na forma explícita de adesão a ideologia da sociedade regida pelo mercado, isso é, ideologia neoliberal, ou se na forma aparentemente crítica de um discurso pós-moderno para o qual todo o projeto de transformação politica consciente da totalidade social redundaria em propostas autoritárias e não 
passaria de uma herança da 'ilusão iluminista' de emancipação humana por meio da razão. (DUARTE, 2011, p. 3-4)

Há, segundo Duarte (2011, p. 3-9), tentativas de "secundarizar a importância do marxismo para a psicologia de Vigotski e sim, torná-la, assim, compatível com os ideários neoliberal e pós-moderno", além de desvalorizar "a transmissão do saber objetivo, na diluição do papel da escola em transmitir esse saber, na descaracterização do papel do professor como alguém que detém um saber a ser transmitido aos seus alunos, na própria negação do ato de ensinar".

A disseminação das ideias de Vigotski em nosso país tem contribuição de intelectuais da educação, além da interpretação de intelectuais europeus e norte-americanos, uma vez que parte das obras que surgiram aqui a partir da década de 1980 adveio de adaptações externas, em especial, dos EUA, sem ser diretamente do idioma russo para o idioma português, com adaptações com geraram questionamentos acerca do tratamento, da fidelidade ao ideário do autor russo (DUARTE, 2011, p. 2).

\section{Vigostki e o processo de mediação}

Pensar a mediação no âmbito educacional nos remete a Vigotski, pois para ele o desenvolvimento cognitivo e o conhecimento acontecem por meio de trocas; das interações entre as pessoas e, também, da relação das pessoas com o mundo, ou seja, "um processo de transferência do social para o individual" (FREITAS, 2012, p. 69). Portanto, a relação do ser humano com o aprendizado e o conhecimento se dá por mediações de duas naturezas: a dos instrumentos e a dos signos, em especial, o signo linguístico. O signo é assim compreendido por Vigotski (1995, p. 83):

Llamamos signos a los estímulos-medios artificiales introducidos por el hombre en la situação psicológica, que cumplen la función de autoestimulación, adjudicando a este término un sentido más amplio y al mismo tempo, más exacto del que se da habitualmente a esa palavra. De acuerdo con nuestra definición, todo estímulo condicional creado por el hombre artificialmente y que se utiliza como medio para dominar la conducta - propia ou ajena - es un signo. $^{2}$

No universo do desenvolvimento a linguagem, ou seja, o signo linguístico torna-se um elemento fundamental para que 0 indivíduo interaja com o conhecimento social, pois o "[...] signo, al principio, es siempre un medio de relación social, un medio de influencia sobre los demas y tan solo despues se transforma en médio de influencia sobre si mismo (VIGOSTKI, 1995, p. 146) ${ }^{3 \prime \prime}$. Nesse contexto, a linguagem tem

\footnotetext{
${ }^{2}$ Chamamos signos aos estímulos - meios artificiais introduzidos pelo homem numa situação psicológica, que cumprem a função de autoestimulação, conferindo a esse termo um sentido mais amplo e, ao mesmo tempo, mais exato do que habitualmente se dá a ele. De acordo com nossa definição, todo estímulo condicional criado artificialmente pelo homem e que se utiliza como meio para dominar o comportamento próprio ou alheio - é um signo. (Tradução nossa)

${ }^{3} \mathrm{O}$ "signo, a princípio, é um meio de relação social, um meio de influência sobre os outros e somente depois se transforma em meio de influencia sobre si mesmo." (Tradução nossa)
} 
preponderância no desenvolvimento e construção do indivíduo, pois "[...] El linguaje, sin embargo, es la función central de las relaciones sociales y de la conducta cultural de la personalidade (VIGOSTKI, 1995, p. 146$148)^{\prime \prime}{ }^{4}$

A atividade mediadora, de acordo om Vigotski, ocorre de duas maneiras, pelas ferramentas/instrumentos ou pelo signo, compreendendo "las herramientas como medios de trabajo, como medios que sirven para dominar los procesos de la naturaleza y el linguaje como medio social de comunicación e interación" ${ }^{5}$ (VIGOSTKI, 1995, p. 93). Se os instrumentos (herramientas) são destinados a interferir em algo externo, por outro lado, os signos medeiam nossas operações psíquicas, internas:

El signo no modifica nada en el objeto de la operacion psicológica: es el médio de que se vale el hombre pra influir psicológicamente, bien en su propia conducta, bien en la dos demás, es un medio para su actividad interior, dirigida a dominar el próprio ser humano: el signo está orientado hacia dentro (VIGOSTKI, 1995, p. 94) ${ }^{6}$

Os signos estão no âmbito das funções psíquicas superiores do desenvolvimento humano e, portanto, o uso deles potencializa a capacidade de atenção e de memória, por isso a memória mediada por eles é mais forte, conforme Vigotski (ZUIN; REYES, 2010, p. 39). Se à linguagem é dada a preponderância de ser a principal mediadora entre o ser humano e o mundo, importa dizer que a linguagem traz consigo o componente ideológico, conforme Bakhtin (1997, p. 36) afirma:

A palavra é fenômeno ideológico por excelência. A realidade toda da palavra é absorvida por sua função de signo. A palavra não comporta nada que esteja ligado a essa função, nada que não tenha sido gerado por ela. A palavra é o modo mais puro e sensível de relação social.

A palavra é mediadora, mas não vem neutra, pois está num contexto discursivo histórico-social e, portanto, carrega em si uma carga ideológica que influenciará a constituição do sujeito, sua consciência, pois os signos formam a consciência individual que, segundo Bakhtin, é "um fato sócio-ideológico", ou seja, os signos são fenômenos do mundo externo e, portanto, possuem fragmentos da realidade, que a reflete e a refrata e, assim, auxiliam na constituição da consciência dos sujeitos (BAKHTIN, 1997).

Ainda é desafio para a educação buscar princípios que auxiliem a mediar a leitura para formar leitores, pois se a linguagem é a principal mediadora entre o indivíduo e o mundo, cada criança ao chegar ao ambiente formal escolar traz consigo conhecimentos da linguagem e do mundo para agregar ao que irá aprender na escola, ou seja, traz leituras

\footnotetext{
${ }^{4}$ A linguagem, porém, é a função central das relações sociais e do comportamento cultural da personalidade. (Tradução nossa)

${ }^{5}$ As ferramentas como meios de trabalho, como meios que servem para dominar os processos da natureza e a linguagem como meio social de comunicação e interação. (Tradução nossa)

${ }^{6}$ O signo não modifica nada no objeto da operação psicológica: é o meio que o homem utiliza para influenciar psicologicamente, em seu próprio comportamento e também nos demais, é um meio para sua atividade interna, direcionada para dominar o próprio ser humano: o signo está orientado para o interno. (Tradução nossa)
} 
do mundo que a rodeia e, portanto, agregará a leitura da escrita ao que já trouxe consigo, o que nos dá a incumbência de mediar esse processo, pois para Freitas (2012, p. 68):

Mediar o desenvolvimento da leitura é exercitar a compreensão do aluno, transformando-o de leitor principiante em leitor ativo. Isso pressupõe desenvolver sua capacidade de ler com segurança, de decodificar com clareza e reconhecer com rapidez as palavras para uma leitura fluente [...] a mediação na leitura acontece na dinâmica da interação. O mediador apoia o leitor auxiliando-o a mobilizar conhecimentos anteriores para desenvolver habilidades específicas para aquela tarefa.

No contexto da mediação da leitura, no âmbito escolar, há que se refletir, entre outros aspectos: Como o mediador, professor ou bibliotecário escolar, poderá conduzir a mediação num processo interativo, respeitando as descobertas, as preferências, o ritmo da compreensão do leitor, sem ser invasivo na elaboração do outro? Como respeitar suas preferências, sem violentar o seu desejo, o seu interesse? Ou ainda, como mediar para que o leitor saiba interagir com o texto para chegar ao seu sentido? Como perguntar ao texto para se chegar ao seu sentido? A mediação para um leitor se dá na mesma perspectiva que para um grupo de 20 ou 30, ou seja, uma sala de aula? Como fazer isso funcionar? A mediação em sala de aula pode ser a mesma da biblioteca escolar?

Essas e muitas outras indagações surgem ao pensarmos na mediação da leitura na escola, uma vez que ela ainda é uma das principais instituições na formação de leitores em larga escala em nosso país. Para Duarte (2011, p. 10-11):

[...] o papel da escola consiste em socializar o saber objetivo historicamente produzido [...] A questão é a de que, ao defender como tarefa central da escola a socialização do saber historicamente produzido, a pedagogia histórico-crítica procura agudizar a contradição da sociedade contemporânea, que se apresenta como sociedade do conhecimento e que, entretanto, ao contrário do que é apregoado, não cria as condições para uma real socialização do saber.

Socializar o saber, entre outros aspectos refere-se às condições de acesso ao conhecimento, à leitura pelos alunos, quer seja de forma mediada pelo professor, pelo bibliotecário e ou pelos espaços que são destinados a isso, em especial, ao uso pedagógico da biblioteca da escola, de modo orientado e também espontâneo. Dessa forma, a frequência à biblioteca não será apenas para pesquisas orientadas em sala de aula, mas também deve proporcionar o livre acesso à busca espontânea que os alunos tenham curiosidade, tudo por meio de uma relação de interação, dialógica, de modo que "[...] envolvidos no processo de mediação efetiva da informação sentem-se acolhidos e reconhecidos como participantes ativos, como protagonistas [...]" (GOMES, 2014, p. 52).

Para Marx e Engels (1999, p. 27-28) "o que os indivíduos são, portanto, depende das condições materiais de sua produção", por isso, 
independente da área do conhecimento, importa oportunizar ao leitor o acesso, a interlocução com a leitura, com a informação, de modo que sejam oferecidas as condições materiais para que ele possa se constituir como sujeito que reflete criticamente, de modo independente as melhores possibilidades para sua própria existência.

\section{Considerações finais}

Educação e CI são áreas afins e que nem sempre dialogam aberta e diretamente acerca de questões epistemológicas afetas a ambas, mas foi possível constatar por meio dos autores consultados que há muito em comum, inclusive perspectivas teóricas que se aproximam e que, portanto, podem juntas contribuir para reflexão mais ampla no âmbito da mediação da leitura e da informação.

Assim, há muito que se perguntar no que tange ao conceito e ao uso da mediação em ambas as áreas como, por exemplo: a mediação no contexto educacional tem os mesmos parâmetros que o contexto da ciência da informação? Como a escola tem buscado elementos para mediar a leitura para a formação de leitores?

Nossa pesquisa, até agora, demonstrou que o vocábulo mediação recebeu contribuições de cada época em que foi utilizado, mas que atualmente, as áreas de Educação e CI utilizam conceitos que se aproximam da perspectiva marxiana, do materialismo histórico, por meio da obra de autores como Vigotski, Bakhtin, Freire e Almeida Júnior.

Nessa perspectiva o sujeito se constitui não apenas do lastro biológico, mas também pelo aspecto cultural, histórico e que, portanto, é pela mediação dos instrumentos e principalmente dos signos, em especial da linguagem, que o homem interpreta o mundo e se forma, absorvendo de fora (social) para dentro (individual) num processo mediado por estímulos que contribuem para o seu desenvolvimento, para construção do conhecimento.

Mas há desafios a serem perscrutados nas áreas em questão, tais como: na CI a perspectiva da mediação acontece, a priori, para um sujeito? Ou a mediação, o processo poderá ser direcionado a um grupo como é na Educação? Na área educacional o pensar na mediação pressupõe as duas direções: individual e grupal, como é o caso de uma turma de sala de aula, com média de 20 a 30 alunos. É a mesma situação? É possível mediar a leitura no ambiente escolar com a contribuição das áreas em conjunto?

O que se evidencia, inicialmente, é que essas áreas são imprescindíveis no processo educativo da sociedade, embora na prática pedagógica escolar, por exemplo, a CI e a Educação não participem conjuntamente, pedagogicamente, de modo a contribuir com o processo formativo. Há uma lacuna quando se investiga a atuação intencional, epistemológica entre as áreas mencionadas, pois quase sempre estão no mesmo espaço físico, mas distantes no diálogo, na interação que beneficiaria a todos os envolvidos, concomitantemente, nesse processo. 
Acreditamos que estudar a mediação em ambas as áreas é o início de uma trajetória que tem um longo percurso a ser trilhado para melhor compreender o âmbito da mediação. Por isso, será necessário investir em pesquisas conjuntas entre Educação e CI, a fim de se compreender e potencializar o arcabouço que se têm a oferecer mutuamente em relação à mediação.

\section{Referências}

ALMEIDA JÚNIOR, O. F. de. Mediação da informação e múltiplas linguagens. CI. Inf., Brasília, v. 2, n. 1, p. 89-103, jan./dez. 2009. Disponível em: <http://inseer.ibict.br/ancib/index.php/tpbci/article/viewFile/17/39>. Acesso em: 7 mar. 2017.

ALMEIDA JÚNIOR, O. F. de. Mediação da Informação: um conceito atualizado. In: BORTOLIN, S.; SANTOS NETO, J. A. dos; SILVA, R. J. da (Org.). Mediação Oral da Informação e da Leitura. Londrina: Abecin, 2015. p. 9-32.

ALMEIDA JÚNIOR, O. F. de; BORTOLIN, S. Mediação da informação e da leitura. In: SILVA, Terezinha Elisabeth da (Org.). Interdisciplinaridade e transversalidade em Ciência da Informação. Recife: Néctar, 2008. p. 6785.

ARANTES, F. M. O uso da oralidade na mediatização dos websites de bibliotecas públicas. 2014. 121f. Mestrado (Ciência da Informação) Universidade Estadual de Londrina, Londrina, 2014. Disponível em: < http://bdtd.ibict.br/vufind/Record/UEL 1d876a767b18fc0f58b2698ea23cde8d >. Acesso em: 7 mar. 2017.

BAKHTIN, M. Marxismo e filosofia da linguagem. São Paulo: Hucitec, 1997.

CARVALHO; R. B. de; MATTOS, F. A. M. Análise mediacional: uma contribuição da Ciência da Informação para o mercado de capitais. Inf. \& Soc.: Est., João Pessoa, v. 18, n. 1, p. 133-145, jan./abr. 2008. Disponível em: <http://www.ies.ufpb.br/ojs/index.php/ies/article/view/1258/1643> . Acesso em: 7 mar. 2017.

CUNHA, A. G. da. Dicionário etimológico Nova Fronteira da Língua Portuguesa. Rio de Janeiro: Nova Fronteira, 1992.

DUARTE, N. Vigotski e o "aprender a aprender": critica as apropriações neoliberais e pós-modernas da teoria vigotskiana. Campinas: Autores Associados, 2011.

FREIRE, P. Pedagogia da autonomia. São Paulo: Paz e Terra, 2003.

FREITAS, V. A. de L. Mediação: estratégia facilitadora da compreensão leitora. In: BORTONI-RICARDO, S. M. et al. (Org.). Leitura e mediação pedagógica. São Paulo: Parábola, 2012. p. 65-85.

GOMES, H. F. A dimensão dialógica, estética, formativa e ética da mediação da informação. Inf. Inf., Londrina, v. 19, n. 2, p. 46-59, 
maio/ago. 2014. Disponível em: <http://www.uel.br/revistas/uel/index.php/informacao/article/view/19994/19090>.

Acesso: 10 dez. 2015.

KONDER, L. O que é dialética. São Paulo: Brasiliense, 1985.

MARX, K.; ENGELS, F. A ideologia alemã: (Feuerbach). São Paulo: Hucitec, 1999.

VYGOTSKY. L. S. Obras escogidas III: historia del desarollo de las funciones psíquicas superiores (1931). Madrid: Visor Distribuciones, 1995.

ZANOLLA, S. R. da S. O conceito de mediação em Vigotski e Adorno. Psicologia e Sociedade, Belo Horizonte, v. 24, n. 1, p. 5-14, 2012. Disponível em: <http://www.scielo.br/scielo.php?script=sci arttext\&pid=S010271822012000100002 >. Acesso em: 7 mar. 2017.

ZUIN, P. B.; REYES, C. R. O ensino da língua materna: dialogando com Vygotsky, Bakhtin e Freire. São Paulo: Ideias e Letras, 2010. 